\title{
Dissociative experiences on ice - peritraumatic and trait dissociation during the cold pressor test
}

Citation for published version (APA):

Giesbrecht, T. M., Smeets, T., \& Merckelbach, H. L. G. J. (2008). Dissociative experiences on ice peritraumatic and trait dissociation during the cold pressor test. Psychiatry Research, 157, 115-121. https://doi.org/10.1016/j.psychres.2006.12.012

Document status and date:

Published: 01/01/2008

DOI:

10.1016/j.psychres.2006.12.012

Document Version:

Publisher's PDF, also known as Version of record

\section{Please check the document version of this publication:}

- A submitted manuscript is the version of the article upon submission and before peer-review. There can be important differences between the submitted version and the official published version of record.

People interested in the research are advised to contact the author for the final version of the publication, or visit the DOI to the publisher's website.

- The final author version and the galley proof are versions of the publication after peer review.

- The final published version features the final layout of the paper including the volume, issue and page numbers.

Link to publication

\footnotetext{
General rights rights.

- You may freely distribute the URL identifying the publication in the public portal. please follow below link for the End User Agreement:

www.umlib.nl/taverne-license

Take down policy

If you believe that this document breaches copyright please contact us at:

repository@maastrichtuniversity.nl

providing details and we will investigate your claim.
}

Copyright and moral rights for the publications made accessible in the public portal are retained by the authors and/or other copyright owners and it is a condition of accessing publications that users recognise and abide by the legal requirements associated with these

- Users may download and print one copy of any publication from the public portal for the purpose of private study or research.

- You may not further distribute the material or use it for any profit-making activity or commercial gain

If the publication is distributed under the terms of Article $25 \mathrm{fa}$ of the Dutch Copyright Act, indicated by the "Taverne" license above, 
Provided for non-commercial research and education use. Not for reproduction, distribution or commercial use.

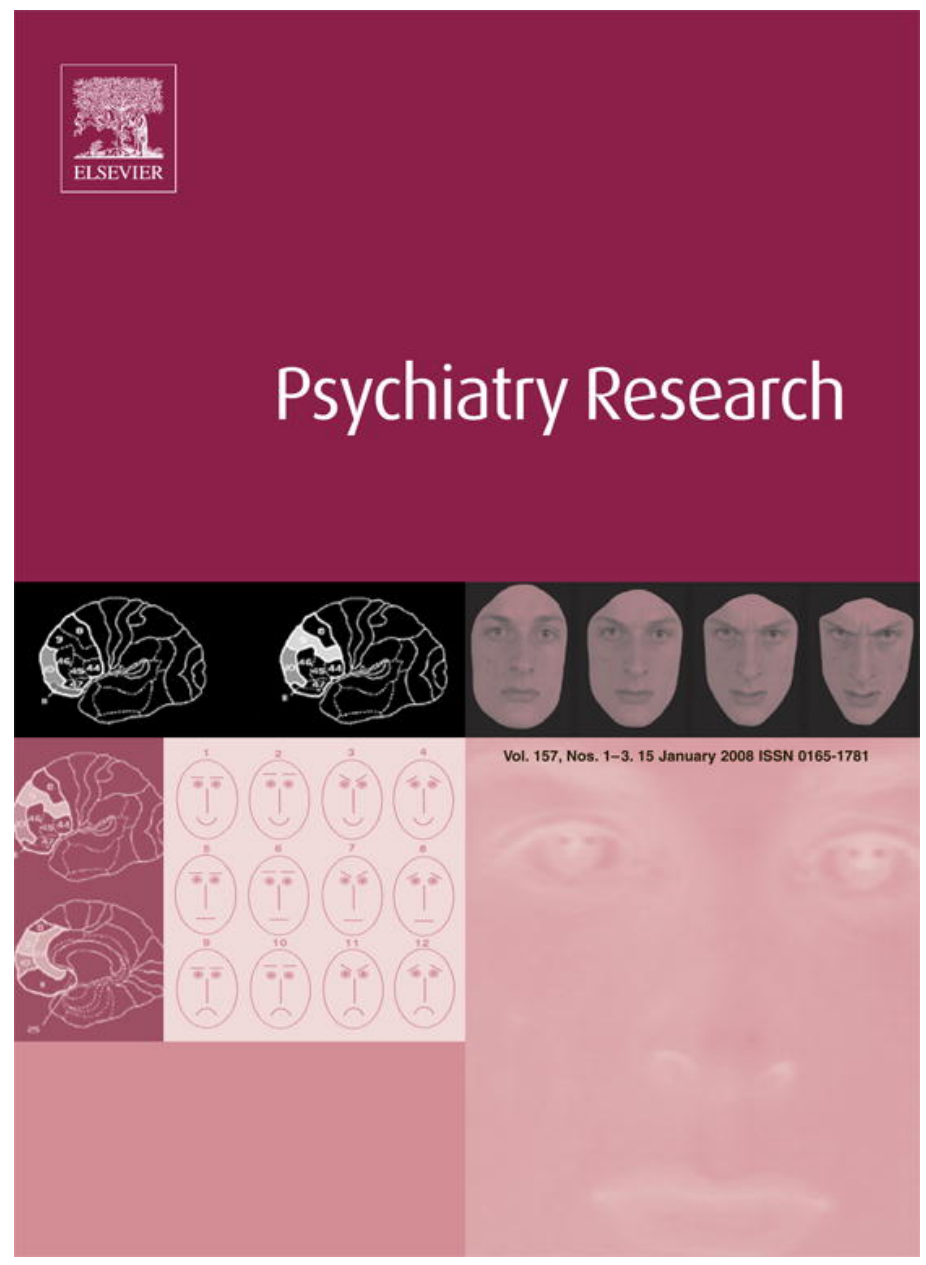

This article was published in an Elsevier journal. The attached copy

is furnished to the author for non-commercial research and education use, including for instruction at the author's institution, sharing with colleagues and providing to institution administration.

Other uses, including reproduction and distribution, or selling or licensing copies, or posting to personal, institutional or third party websites are prohibited.

In most cases authors are permitted to post their version of the article (e.g. in Word or Tex form) to their personal website or institutional repository. Authors requiring further information regarding Elsevier's archiving and manuscript policies are encouraged to visit: 


\title{
Dissociative experiences on ice - Peritraumatic and trait dissociation during the cold pressor test
}

\author{
Timo Giesbrecht*, Tom Smeets, Harald Merckelbach \\ Department of Experimental Psychology, Maastricht University, Maastricht, The Netherlands
}

Received 10 May 2006; received in revised form 30 August 2006; accepted 11 December 2006

\begin{abstract}
The present study investigated the relationship between trait dissociation and peritraumatic dissociation during acute painful stimulation. In a sample of 70 undergraduate students, peritraumatic dissociation was induced by means of a cold pressor test, which basically consists of participants holding an arm in ice water for as long as possible. Results indicate that heightened trait dissociation scores were related to shorter durations that participants could sustain the task. However, trait dissociation was not associated with increases in acute dissociative symptoms (i.e., peritraumatic dissociation). These findings are in sharp contrast to the defensive function ascribed to both types of dissociation and also the commonly held assumption that peritraumatic and trait dissociation are intimately linked.
\end{abstract}

(C) 2006 Elsevier Ireland Ltd. All rights reserved.

Keywords: Trait dissociation; Pain; Peritraumatic dissociation; Cold pressor test

\section{Introduction}

More than 100 years ago, Janet (1889) coined the term of psychological dissociation in his book L'Automatisme Psychologique to denote a defensive response to psychological trauma. Following a tradition that started with Janet, recent clinical literature emphasizes the defensive properties of dissociation (Sanders and Giolas, 1991; Classen et al., 1993; Zlotnick et al., 1996; Gershuny and Thayer, 1999).

It is widely assumed that dissociative experiences are triggered by the acute stress that accompanies motor vehicle accidents (Lanius et al., 2003), rape (Griffin et al.,

\footnotetext{
* Corresponding author. Department of Experimental Psychology, Maastricht University, PO Box 616, 6200 MD, Maastricht, The Netherlands. Tel.: +31 43388 2178; fax: +31 433884196 .

E-mail address: T.Giesbrecht@psychology.unimaas.nl (T. Giesbrecht).
}

1997), or other traumatic experiences. These acute dissociative experiences have been termed peritraumatic dissociation and involve alterations in cognitive and perceptual functioning when faced with a traumatic event (Candel and Merckelbach, 2004). During such an event, depersonalization, derealization, narrowing of attention, time distortion, confusion, and psychogenic amnesia might occur (Spiegel and Cardena, 1991). Peritraumatic dissociation is considered a "partially adaptive response to trauma" (Ladwig et al., 2002, p. 41), as it is assumed to protect victims of psychotraumatic events against the overwhelming exposure to threatening stimuli. However, many authors (e.g., van der Kolk and van der Hart, 1989) believe that these experiences hamper processing of trauma-related memories, thereby promoting future posttraumatic stress disorder (PTSD).

Following Janet (1889), it is also widely believed that peritraumatic dissociative phenomena during acute aversive experiences might take a more chronic course 
and then evolve into trait-like experiences - sometimes referred to as trait (i.e., persistent) dissociation. This would mean that peritraumatic dissociation should promote the habitual use of dissociation as a response to even minor stressors (Gershuny and Thayer, 1999). By this view, peritraumatic dissociation represents the pathway to trait dissociation and this notion implies that peritraumatic and trait dissociation are intimately linked and represent the manifestation of a common (defense) mechanism.

Interestingly, evidence is accumulating that peritraumatic dissociative experiences might be a common and non-pathological response during acute stress. For example, Sterlini and Bryant (2002) demonstrated that one third of their healthy participants reported substantial levels of peritraumatic dissociation during their first skydive, whereas Morgan et al. (2001) reported that during stressful army survival training $96 \%$ of the soldiers had dissociative experiences. In addition, Leonard et al. (1999) found that even under nonstressful situations, such as dot-staring or the administration of pulsed photic and audio stimulation, dissociative experience can be readily elicited in healthy participants. In line with the notion that trait and peritraumatic dissociation are interrelated, these authors reported that individuals scoring high on trait dissociation, as indexed by the Dissociative Experiences Scale (DES; Bernstein and Putnam, 1986), also reported more dissociative responses during these procedures as compared with participants scoring low on the DES. In contrast, Sterlini and Bryant (2002) found that traitlike dissociative tendencies, as measured by the Tellegen Absorption Scale (TAS; Tellegen and Atkinson, 1974), do not predict peritraumatic dissociation during skydiving.

The aim of the present study was to investigate whether trait dissociation and peritraumatic dissociation are intimately related, as is often assumed in the clinical literature (van der Kolk and van der Hart, 1989; Holmes et al., 2005). We induced physiological stress by means of a cold pressor test (CPT; Bohus et al., 2000), so as to evoke peritraumatic dissociative responses. ${ }^{1}$ If trait dissociation and peritraumatic dissociation are indeed interrelated, one would expect that individuals who score high on trait dissociation would also exhibit heightened levels of peritraumatic symptoms during the CPT. Moreover, as the more pathological manifestations of trait dissociation (i.e., amnesia and depersonalization), as opposed to the benign (i.e., absorption) ones,

\footnotetext{
${ }^{1}$ The term "peritraumatic dissociation" in the present context does not imply that the cold pressor task is a traumatic event.
}

are thought to be indicative of traumatic etiology, we hypothesized that the overlap between trait dissociation and peritraumatic dissociation would be carried by individual differences in amnesia and depersonalization. We also investigated whether these dissociative symptoms might be functional. If dissociation is, indeed, the manifestation of a defense mechanism, this would imply that individuals who dissociate extensively during the CPT should be capable of enduring the task longer. Interestingly, the only study (Agargun et al., 1998) that explored the relationship between pain and trait dissociation found the opposite pattern, with high-DES individuals having reduced pain tolerance levels.

\section{Method}

\subsection{Participants}

Participants were 70 undergraduate (47 women) students enrolled at Maastricht University. Their mean age was 21.57 years (S.D. $=2.93$; range: 19 to 35 years). Participants gave written informed consent and received a small financial compensation for their participation. The study was approved by the standing ethical committee of the Faculty of Psychology, Maastricht University.

\subsection{Psychometric instruments}

Dissociative Experiences Scale (DES; Cronbach's alpha $=0.92$; Bernstein and Putnam, 1986). The DES is a self-report scale asking respondents to indicate on 100$\mathrm{mm}$ Visual-Analogue Scales to what extent they experience 28 dissociative phenomena in daily life. Examples of such phenomena include feelings of depersonalization, derealization, and psychogenic amnesia. A total DES score can be obtained by averaging all items. In a meta-analysis, van IJzendoorn and Schuengel (1996) provide evidence for the sound psychometric properties of the DES. In addition to the total DES score, we calculated separate subscale scores following the three-factor solution proposed by Ross et al. (1995), Sanders and Green (1994), and Carlson et al. (1991). These were the subscales amnesia (Cronbach's alpha $=0.79$ ), absorption and imaginative involvement $($ Cronbach's alpha $=0.84)$, and depersonalization and derealization (Cronbach's alpha $=0.74$ ).

Peritraumatic Dissociative Experiences Questionnaire (PDEQ; Marshall et al., 2002). The PDEQ is the most widely used self-report measure of peritraumatic dissociative reactions and consists of eight items. These items quantify the amount of acute dissociation that people 
experience during a specific event. Respondents are asked to indicate on a 5-point scale (anchors: $1=$ not at all true, $5=$ extremely true) to what extent they experienced particular dissociative symptoms (e.g., "I felt confused or couldn't make sense of what was happening"). During the present study, the Dutch translation of the modified version was employed (Marshall et al., 2002). This version of the PDEQ possesses adequate internal consistency, test-retest reliability, and convergent-divergent validity (Marshall et al., 2002). The PDEQ was administered twice, once before (Cronbach's alpha= $0.79)$ and once after (Cronbach's alpha $=0.81)$ participants had been exposed to the CPT.

\subsection{Cold pressor test}

The cold pressor test (CPT) was selected as an ethical, low-risk procedure to expose participants to painful stressors (Bohus et al., 2000). The CPT is a widely used technique in medical research and induces a robust and reliable stress response (Cahill et al., 2003; Mitchell et al., 2004). Following the typical CPT procedure, participants in the current study were instructed to hold their dominant arm up to the elbow as long as possible in ice-cold water (with a maximum of $4 \mathrm{~min}$ ). Water temperature was maintained at $1-3{ }^{\circ} \mathrm{C}$.

\subsection{Procedure}

Participants were tested individually in the laboratory with an experimenter present. Firstly, the DES and a first PDEQ measure were administered. Participants were instructed to relate the PDEQ to the last 4 min before they arrived at the laboratory (i.e., PDEQ1), such that it served as a baseline measure of acute dissociative symptoms before our experimental manipulation. Next, participants had to complete an unrelated working memory test that served as a filler task. After completion of this task, participants were exposed to the CPT. The time (in s) that participants tolerated the CPT was recorded. Subsequently, participants completed the PDEQ again (i.e., PDEQ2). This time, however, the PDEQ pertained to their experiences during the CPT. Finally, participants were fully debriefed and thanked for their participation.

\subsection{Data analysis}

Statistical analyses were performed using SPSS software. Cronbach's alpha coefficients were calculated to estimate the DES's and PDEQ's internal consistency. PDEQ scores before the CPT and after the CPT were compared by means of an independent $t$-test. As the average time participants could tolerate the CPT was distributed non-normally, we performed a logtransformation. ${ }^{2}$ Pearson product-moment correlations were calculated between the DES, PDEQ, and the time participants could tolerate the CPT. To test the hypothesis that trait dissociation is related to an increase of peritraumatic dissociation under acute stress, we calculated partial correlations between the DES and its subscales and the PDEQ after the CPT (i.e., PDEQ2), while statistically controlling for acute dissociation before the CPT (i.e., PDEQ1). Moreover, two separate forward stepwise multiple regression analyses were conducted. In a first analysis, the unique influence of both acute dissociation before the CPT (i.e., PDEQ1) and trait dissociation as represented by the DES and its subscales on peritraumatic dissociation after the CPT (PDEQ2) was quantified. In a second analysis, the unique influence of trait dissociation and acute dissociation before (PDEQ1) and after the CPT (PDEQ2) on tolerance times was investigated. Moreover, both analyses offered the possibility to control for gender and age.

\section{Results}

Mean DES and PDEQ scores before (PDEQ1) and after the CPT (PDEQ2) were 14.46 (S.D. $=9.25$, range 0.89 to 40 ), 9.36 (S.D. $=2.55$, range 8 to 19 ), and 11.60 (S.D. $=4.39$, range 8 to 27 ), respectively. Mean scores on the DES's amnesia, absorption, and depersonalization subscales were 9.58 (S.D. $=8.42$ ), 23.31 (S.D. $=$ 13.36), and 6.39 (S.D.=7.13), respectively. Peritraumatic dissociation, as measured by the PDEQ, significantly increased after the CPT compared with the baseline measure of acute dissociative symptoms, $t(69)=4.87$, $P<0.01$, partial $\eta^{2}=0.26$. This shows that the CPT succeeded in inducing heightened levels of peritraumatic dissociative symptoms in our participants.

Table 1 presents Pearson product-moment correlations between the DES and the PDEQ. DES scores were related to both the PDEQ administered before and after the CPT. Partial correlations between the DES total score, the DES amnesia and depersonalization subscale, and the PDEQ2 that controlled statistically for acute dissociation before the CPT were non-significant (all $P ' s>0.18)$. The absorption subscale of the DES was, however, significantly related to the increase in peritraumatic dissociation after controlling for acute dissociation before the CPT (see Table 1).

\footnotetext{
${ }^{2}$ A similar correlational pattern was obtained when CPT tolerance was subjected to a square-root transformation.
} 
Table 1

Pearson correlations between the Dissociative Experiences Scale (DES), the amnesia, absorption, and depersonalization subscales of the DES, the Peritraumatic Dissociative Experiences Questionnaire before (PDEQ1) and after (PDEQ2) the cold pressor test, and the log-transformed time participants could tolerate the test (duration) in an undergraduate sample $(N=70)$

\begin{tabular}{|c|c|c|c|c|c|c|c|}
\hline & DES & Amnesia & Absorption & Depersonalization & PDEQ1 & PDEQ2 & PDEQ2 ${ }_{\text {partial }}$ \\
\hline DES & - & & & & & & 0.16 \\
\hline Amnesia & $0.89 *$ & - & & & & & 0.08 \\
\hline Absorption & $0.90 *$ & $0.67 *$ & - & & & & $0.26 *$ \\
\hline Depersonalization & $0.72 *$ & $0.59 *$ & $0.57 *$ & - & & & 0.11 \\
\hline PDEQ1 & $0.39 *$ & $0.28 *$ & $0.37 *$ & $0.54 *$ & - & & - \\
\hline PDEQ2 & $0.32 *$ & 0.21 & $0.39 *$ & $0.35 *$ & $0.49 *$ & - & - \\
\hline Duration & $-0.25 *$ & $-0.27 *$ & -0.22 & -0.13 & -0.17 & -0.08 & 0.00 \\
\hline
\end{tabular}

Partial correlations with the PDEQ2 while controlling statistically for acute dissociation before the CPT (i.e., PDEQ1) are also presented (PDEQ2 2 partial).

* Correlation is significant at the 0.05 level (2-tailed).

To investigate relationships between pain tolerance, peritraumatic dissociation, and (more) clinically relevant levels of dissociative experiences, we extracted two subsamples from our original sample, namely a low dissociators group $(\mathrm{DES}<10)$ and a high dissociators group (DES $>25$ ). Note that the cut-off used for selecting the high-DES group corresponds with recommendations in the clinical literature (e.g., Draijer and Boon, 1993). This approach resulted in a high-DES $(N=11)$ and a low DES $(N=28)$ group with mean DES scores of 30.88 (S.D. $=4.66$ ) and 6.34 (S.D. $=2.69$ ), respectively. Next, we investigated whether the highDES group would exhibit more pronounced acute dissociative symptom than the low DES group. A univariate analysis of variance with DES groups as between-subjects factor, acute dissociation before the CPT as covariate (i.e., PDEQ1), and peritraumatic dissociation after the CPT (i.e., PDEQ2) as dependent variable did not yield a significant difference between the high- and the low-DES group, $F(1,36)=0.70$, $P>0.05$.

Forward stepwise multiple regression analysis with peritraumatic dissociation after the CPT as dependent variable indicated that the PDEQ1 accounted for 23\%, while participants' DES-absorption scores accounted for a further $4 \%$ of the variance in peritraumatic dissociation (i.e., PDEQ2; see Table 2). Moreover, age and gender were unrelated to peritraumatic dissociation after the CPT.

The average time participants could endure the CPT was $138.25 \mathrm{~s}$ (S.D. $=91.83$, range 18 to $240 \mathrm{~s}$ ). Pearson product-moment correlations between trait dissociation, peritraumatic dissociation, and log-transformed CPT tolerance times are presented in Table 1. While trait dissociation, as measured by the DES, was inversely related to the time participants could endure the task, peritraumatic dissociative symptoms appeared to be unrelated to tolerance times. An independent $t$-test comparing endurance times for high-DES $(>25)$ and low-DES $(<10)$ participants yielded similar results, with high dissociators tending to have shorter tolerance times, an effect that was borderline significant, $t(37)=$ 1.96, $P=0.06$. Moreover, participants in the upper quartile $(N=16, M=18.19$, S.D. $=4.31)$ of the PDEQ2 could not endure the CPT longer than participants in the lowest quartile $(N=19, M=8$, S.D. $=0), t(33)=0.63$, $P>0.05$. Note that PDEQ levels in our upper quartile group approach levels reported by individuals severely traumatized through community violence (e.g., Jaycox et al., 2003).

Table 2 also summarizes the results of the forward stepwise multiple regression analysis with endurance times as dependent variable. This analysis indicates that gender accounted for $11 \%$, while participants' DES scores accounted for a further $4 \%$ of the variance in

Table 2

Summary of forward stepwise regressions with peritraumatic dissociative experiences after the CPT (i.e., PDEQ2) and the log-transformed time the participants could endure the test (i.e., duration) as dependent variable in an undergraduate sample $(N=70)$

\begin{tabular}{lllllllll}
\hline Dependent variable & $\begin{array}{l}\text { Adjusted } \\
\text { R2 }\end{array}$ & & & SE & Beta & $t$ & $P$ \\
\hline PDEQ2 $^{\mathrm{a}}$ & & PDEQ1 & 0.23 & 0.69 & 0.11 & 0.40 & 3.64 & 0.00 \\
& DES- & 0.27 & 0.01 & 0.01 & 0.24 & 2.19 & 0.03 \\
& $\begin{array}{l}\text { absorption } \\
\text { Duration }^{\mathrm{b}}\end{array}$ & & & & & & & \\
& Gender & 0.11 & -0.62 & 0.21 & -0.33 & -3.00 & 0.00 \\
& DES & 0.15 & -0.02 & 0.01 & -0.23 & -2.05 & 0.04 \\
\hline
\end{tabular}

The variables in the forward stepwise regression were:

${ }^{\mathrm{a}}$ Gender, age, Dissociative Experiences Questionnaire (DES) and DES amnesia, absorption, and depersonalization subscales, Peritraumatic Dissociative Experiences Questionnaire prior to the Cold Pressor Task. ${ }^{\mathrm{b}}$ Gender, age, Dissociative Experiences Questionnaire (DES) and DES amnesia, absorption, and depersonalization subscale, Peritraumatic Dissociative Experiences Questionnaire before and after the Cold Pressor Task. 
endurance times. More specifically, men could endure the CPT better than women, and heightened levels of trait dissociation were associated with shorter endurance times. It is worthy of note that the gender-DES interaction was not significant.

\section{Discussion}

The most important findings of our study can be catalogued as follows: Firstly, the CPT successfully induced peritraumatic dissociation, as shown by an increase in acute dissociative symptoms. Secondly, trait dissociation was related to acute dissociation, both before and after our manipulation. However, of the DES subscales, only the absorption subscale was related to peritraumatic dissociation after the CPT manipulation, while all other measures of dissociation were, at least in this sample of undergraduate students, unrelated to acute dissociative responses. Thirdly, in stark contrast to the notion that trait dissociation represents a defensive mechanism, high levels of trait dissociation were related to shorter rather than longer times for which participants could endure the CPT. Fourthly, this pattern of findings remained essentially unchanged when our analyses were based on more clinically relevant groups, that is, individuals scoring above the clinical cut-off of the DES or individuals within the upper quartile of the PDEQ.

Contrary to the notion that dissociation serves a defensive purpose, low dissociators could endure CPTinduced pain longer than high dissociators. While being at odds with widespread beliefs about the function of dissociation as an adaptive defense (e.g., Steinberg, 2001; Holmes et al., 2005), this finding is in line with the only other published study that investigated the link between dissociation and pain (Agargun et al., 1998). The negative relationship between dissociation and pain tolerance concurs with other findings from our laboratory. In one study, for example, we found heightened levels of dissociation to be related to hyper-responsivity to an emotional video fragment (Giesbrecht et al., 2007a). In another study (Giesbrecht et al., 2007b), the defensive properties of dissociation were investigated with the Trier Social Stress Test (Kirschbaum et al., 1993), which is a reliable laboratory procedure to induce psychological stress. In that study, high dissociators reported experiencing more subjective stress than did low dissociators. In sum, these findings seem to indicate that dissociation might not be adaptive, at least not in these laboratory contexts. Assuming that defense mechanisms are either adaptive or maladaptive, dissociation in the laboratory context might reflect a maladaptive mechanism or might be no defense mechanism at all. However, our approach does not allow ruling out either possibility. Alternatively, one could argue that dissociation is adaptive with respect to CPT endurance in that individuals would have been able to endure the CPT for an even briefer period without their learned capacity to dissociate. This interpretation of our data is not persuasive as it implies that individuals high on trait dissociation should have been successful using dissociation. On the contrary, state dissociation was unrelated to times participants could endure the CPT.

The present findings contribute to our understanding of the (proposed) relationship between trait and peritraumatic dissociation. They clearly illustrate that the link between trait and peritraumatic dissociation is complex: the constructs are related to one other, but neither dissociative experiences in general nor the pathological facets of dissociation can predict changes in acute dissociation. This is in line with Sterlini and Bryant (2002), who found that hyperarousal and to a lesser extent anxiety, but not trait dissociation, contributed to peritraumatic dissociation during skydiving. However, both Sterlini and Bryant's (2002) study and our study relied on healthy volunteers. On the other hand, the finding in our study remained essentially the same when comparisons were limited to individuals with DES levels above the clinical cut-off for dissociative disorders (Draijer and Boon, 1993) and individuals with low dissociation levels. Nevertheless, our findings cannot be easily generalized to severely traumatized individuals with prominent dissociative symptomatology. For example, it is possible that our healthy participants have simply not acquired the tendency to dissociate during stressful events, because most of them have never experienced a severe traumatic event. However, surveys have found prevalence rates of childhood abuse that do not support this assumption. Unfortunately, childhood abuse is rather common, in both undergraduate and college samples. For example, $17 \%$ of college students report childhood sexual abuse in the form of sexual intercourse (Rind et al., 1998). Given these estimates, it is unlikely that our sample had a background that was largely free of traumatic experiences. Self-reported trauma was, however, not tapped in the current study. Therefore, the links between both types of dissociation, traumatic experiences, and pain tolerance warrant further study, preferably in clinical samples.

Another limitation of the present study might be that we employed a moderately stressful task of a limited duration. Consequently, the CPT might not have been able to elicit substantial levels of peritraumatic dissociation. 
Although this represents an important limitation of our study, there are two reasons why our findings are informative. Firstly, our findings parallel those of Sterlini and Bryant (2002), who studied peritraumatic dissociation during an extremely distressing event (i.e., first parachute jump). Secondly and more importantly, while our own study relied on a moderately distressing task, a substantial minority of our participants exhibited a degree of peritraumatic dissociation that approached levels reported in studies carried out in naturalistic settings, such as in victims of community violence (Jaycox et al., 2003). When we restricted our analyses to the subsample of individuals who dissociated extensively during the CPT, our pattern of findings did not change. Nevertheless, our findings warrant replication in clinically relevant groups such as victims of traffic accidents.

To conclude at least in our sample of undergraduate students, trait dissociation did not possess any adaptive defensive (i.e., pain-reducing) properties. In fact, the contrary appeared to be true. The current study adds to a body of findings that is difficult to reconcile with the alleged defensive function of trait dissociation (Candel et al., 2003; Merckelbach and Jelicic, 2004).

\section{Acknowledgements}

This study was supported by a grant from the Netherlands Organisation for Scientific Research (N.W.O., grant number 402-01-088-D). We thank Sophie Stegeman, Clint Werner, Mi Mi Nuyens, Frauke Streuff, Nora de la Parra, and Michelle Moerel for their assistance in data collection.

\section{References}

Agargun, M.Y., Tekeoglu, I., Kara, H., Adak, B., Ercan, M., 1998. Hypnotizability, pain threshold, and dissociative experiences. Biological Psychiatry 44, 69-71.

Bernstein, E.M., Putnam, F.W., 1986. Development, reliability, and validity of a dissociation scale. Journal of Nervous and Mental Disease 174, 727-735.

Bohus, M., Limberger, M., Ebner, U., Glocker, F.X., Schwarz, B., Wernz, M., Lieb, K., 2000. Pain perception during self-reported distress and calmness in patients with borderline personality disorder and selfmutilating behavior. Psychiatry Research 95, 251-260.

Cahill, L., Gorski, L., Le, K., 2003. Enhanced human memory consolidation with post-learning stress: interaction with the degree of arousal at encoding. Learning and Memory 10, 270-274.

Candel, I., Merckelbach, H., 2004. Peritraumatic dissociation as a predictor of PTSD: a critical review. Comprehensive Psychiatry 45, 44-50.

Candel, I., Merckelbach, H., Kuijpers, M., 2003. Dissociative experiences are related to commissions in emotional memory. Behaviour Research and Therapy 41, 719-725.

Carlson, E.B., Putnam, F.W., Ross, C.A., Anderson, G., Clark, P., Torem, M., et al., 1991. Factor analysis of the Dissociative
Experiences Scale: a multicenter study. In: Braun, B.G., Carlson, E.B. (Eds.), Proceedings of the Eighth International Conference on Multiple Personality and Dissociative States. Rush, Chicago.

Classen, C., Koopman, C., Spiegel, D., 1993. Trauma and dissociation. Bulletin of the Menninger Clinic 57, 178-194.

Draijer, N., Boon, S., 1993. The validation of the Dissociative Experiences Scale against the criterion of the SCID-D, using receiver operating characteristics (ROC) analysis. Dissociation 6, 28-37.

Gershuny, B.S., Thayer, J.F., 1999. Relations among psychological trauma, dissociative phenomena, and trauma-related distress: a review and integration. Clinical Psychology Review 19, 631-637.

Giesbrecht, T., Geraerts, E., Merckelbach, H., 2007a. Dissociation, memory commission errors, and heightened autonomic reactivity. Psychiatry Research 150, 277-285.

Giesbrecht, T., Smeets, T., Merckelbach, H., Jelicic, M., $2007 \mathrm{~b}$. Depersonalization experiences in undergraduates are related to heightened stress cortisol responses. Journal of Nervous and Mental Disease 195, 282-287.

Griffin, M.G., Resick, P.A., Mechanic, M.B., 1997. Objective assessment of peritraumatic dissociation: psychophysiological indicators. American Journal of Psychiatry 154, 1081-1088.

Holmes, E.A., Brown, R.J., Mansell, W., Fearon, R., Hunter, E.C.M., Frasquilho, F., Oakley, D.A., 2005. Are there two qualitatively distinct forms of dissociation? A review and some clinical implications. Clinical Psychology Review 25, 1-23.

Janet, P., 1889. L’Automatisme Psychologique. Félix Alcan. New Edition: Société Pierre Janet, Paris, 1973, Paris.

Jaycox, L.H., Marshall, G.N., Orlando, M., 2003. Predictors of acute distress among young adults injured by community violence. Journal of Traumatic Stress 16, 237-245.

Kirschbaum, C., Pirke, K.M., Hellhammer, D.H., 1993. The 'Trier Social Stress Test': a tool for investigating psychobiological stress responses in a laboratory setting. Neuropsychobiology $28,76-81$.

Ladwig, K.H., Marten-Mittag, B., Deisenhofer, I., Hofmann, B., Schapperer, J., Weyerbrock, S., Erazo, N., Schmitt, C., 2002. Psychophysiological correlates of peritraumatic dissociative responses in survivors of life-threatening cardiac events. Psychopathology 35, 241-248.

Lanius, R.A., Hopper, J.W., Menon, R.S., 2003. Individual differences in a husband and wife who developed PTSD after a motor vehicle accident: a functional MRI case study. American Journal of Psychiatry 160, 667-669.

Leonard, K.N., Telch, M.J., Harrington, P.J., 1999. Dissociation in the laboratory: a comparison of strategies. Behaviour Research and Therapy 37, 49-61.

Marshall, G.N., Orlando, M., Jaycox, L.H., Foy, D.W., Belzberg, H., 2002. Development and validation of a modified version of the Peritraumatic Dissociative Experiences Questionnaire. Psychological Assessment 14, 123-134.

Merckelbach, H., Jelicic, M., 2004. Dissociative symptoms are related to endorsement of vague trauma items. Comprehensive Psychiatry $45,70-75$.

Mitchell, L.A., MacDonald, R.A., Brodie, E.E., 2004. Temperature and the cold pressor test. Journal of Pain 5, 233-237.

Morgan III, C.A., Hazlett, G., Wang, S., Richardson Jr., E.G., Schnurr, P., Southwick, S.M., 2001. Symptoms of dissociation in humans experiencing acute, uncontrollable stress: a prospective investigation. American Journal of Psychiatry 158, 1239-1247.

Rind, B., Tromovitch, P., Bauserman, R., 1998. A meta-analytic examination of assumed properties of child sexual abuse using college samples. Psychological Bulletin 124, 22-53. 
Ross, C.A., Ellason, J.W., Anderson, G., 1995. A factor analysis of the Dissociative Experiences Scale (DES) in dissociative identity disorder. Dissociation 8, 229-235.

Sanders, B., Giolas, M.H., 1991. Dissociation and childhood trauma in psychologically disturbed adolescents. American Journal of Psychiatry 148, 50-54.

Sanders, B., Green, A., 1994. The factor structure of dissociative experiences in college students. Dissociation 7, 23-27.

Spiegel, D., Cardena, E., 1991. Disintegrated experience: the dissociative disorders revisited. Journal of Abnormal Psychology 100, 366-378.

Steinberg, M., 2001. The Stranger in the Mirror: Dissociation - The Hidden Epidemic. Cliff Street Books, New York.

Sterlini, G.L., Bryant, R.A., 2002. Hyperarousal and dissociation: a study of novice skydivers. Behaviour Research and Therapy 40, $431-437$.
Tellegen, A., Atkinson, G., 1974. Openness to absorbing and selfaltering experiences ("absorption"), a trait related to hypnotic susceptibility. Journal of Abnormal Psychology 83, 268-277.

van der Kolk, B.A., van der Hart, O., 1989. Pierre Janet and the breakdown of adaptation in psychological trauma. American Journal of Psychiatry 146, 1530-1540.

van IJzendoorn, M.H., Schuengel, C., 1996. The measurement of dissociation in normal and clinical populations: meta-analytic validation of the Dissociative Experience Scale (DES). Clinical Psychology Review 16, 365-382.

Zlotnick, C., Shea, M.T., Pearlstein, T., Simpson, E., Costello, E., Begin, A., 1996. The relationship between dissociative symptoms, alexithymia, impulsivity, sexual abuse, and self-mutilation. Comprehensive Psychiatry 37, 12-16. 